\title{
A Bird's Eye View of the Notion of Translation
}

\author{
Misbah M.D. Al-Sulaimaan \\ Ph.D. Professor \\ Email: mmd_alsulaimaan@yahoo.com, \\ misbah.alsulaimaan@Ifu.edu.krd
}

\section{Lubna M. Khoshaba}

M.A. Asst. Lecturer

Email: lubna.markus@lfu.edu.krd

Department of English - College of Education and Languages Lebanese-French University - Erbil Kurdistan Region -Iraq

\begin{abstract}
Translation is a very comprehensive area. It has been viewed differently by theorists of translation. The main reason behind that is that there are many factors that affect its notion. Among these factors are: (1) to whom we translate,(2) from whom we translate,(3) what is the intention of the speaker or the writer or the addressor? (4) what are the needs of the receivers, or the addressees, or the readers ?(5) are we after didactic purposes for knowing the similarities and differences between languages in question or are we after communicating other communities or nations? (6) are we after transferring the meaning conveyed by the speaker or writer or sender? (7) or are we after the force of the text(pragmatically speaking)? ,among so many questions that can be raised about this comprehensive living notion. As is well-known, translation has been defined in terms of finding equivalence, and in terms of transference of meaning. It has also given so many notions such as process, product, horizontal, vertical, linear, lineal, semantic, communication, interlingual, intra-lingual, intersemiotic, literary, non-literary. This paper will give an explanation to the notion of translation and answer the questions that have been raised so as to arrive at removing the ambiguities of such comprehensive notion of translation. Then, in the light of the findings and conclusions, the paper will give some recommendations for the translators and interpreters.
\end{abstract}

Keywords: Translation, Transference, Equivalence, Process, Product, Semantic, Communicative, Literary and Non-literary. 


\section{Introduction:}

Writings on the subject of translation go far back in recorded history. The practice of translation was discussed for example, by Cicero and Horace (first century before common era, BCE) and St Jerome (fourth century / common era, CE). Their writings were to exert an important influence up until the twentieth century. This chapter describes some of the major issues that are discussed in writings about translation up to the beginning of the twenty first century. This huge range of over two thousand years, beginning with Cicero in the first century BCE, focuses on the "literal vs. free" translation debate, an imprecise and circular debate from which theorists have emerged only in the last fifty years. This chapter also describes some of the classic writings on translation over the years, a selection of the most well-known and readily available sources such as those by Egyptians, Greeks, Romans, Arabs, and Western Scholars up to the Modern Age (Era). In what follows, we will initiate discussion on some of the key issues, views, and principles concerning translation.

Translation is an incredibly wide notion which can be understood in different ways. For instance, one may talk of translation as a process or a product, and identify such sub-types as literary translation, technical translation, legal translation, journalistic translation, etc. Moreover, while more typically it just refers to the transference of written texts, the term sometimes also includes 'interpreting'. Not surprisingly many formal definitions have also been offered, each of which reflect a particular underlying theoretical model. The linguistic aspects of the translation process have been encapsulated in a large number of definitions, mostly dating from the 1960s or earlier (Shuttleworth and Cowie, 1997). Thus, Catford (1965), for example, defines translation as "the replacement of textual material in one language (SL) by equivalent textual material in another language (TL)". However, as Sager (1994) points out, most older definitions of this type tend to centre around the importance of maintaining some kind of 'equivalence' between ST and TT. Thus for Sager (1994), Jokobson's is in this sense innovative. Jakobson (1966) sees translation in semiotic terms as an interpretation of verbal signs by means of some other languages understanding the translation process as a substitution of "message in one language not for separate code units, but for entire messages in some other languages". Lawendowski (1978) holds the same view when he defined translation as "the transference of meaning from one set of language signs to another set of language signs". An approach based on the importance of preserving the effect of the original is given by Nida and Taber (1982). They say "translation consists in reproducing in the receptor language the closest natural equivalence of the source language message, first in terms of meaning and secondly in terms of style. Nord (1991) defines translation as "the production of a functional target text maintaining a relationship with a given source text that is 
specified according to the intended or demanded function of the TT. Finally, to reflect the environment in which much professional translation activity takes place, Sager (1994) suggests widening previous definitions by specifying that "translation is an externally motivated industrial activity, supported by information technology, which is diversified in response to the particular needs of this form of communication (for further details, see Bassnett,1991; Hatim, 1997; Holmes, 1970; Al-Sulaimaan and Sa'eed,2007 ).

From what has been said so far, one can say that translation has been viewed either in terms of finding equivalence or in terms of transference of meaning. In what follows, we will explain these types in some details.

\section{A Brief History of the Discipline}

Translation is a very old activity. It can be considered as a unique human achievement that no other animal could share. It goes back to the Egyptian Kingdom (3000 BC) where inscriptions in two languages were found. It became an important factor in the west about the year $300 \mathrm{BC}$, when the Romans took over many elements of Greek culture. During the $12^{\text {th }}$ century, the West came into contact with Islam in Spain. During that period of time, there were two factors that helped the process of translation to be widely spread. Those factors were: (1) the qualitative differences between cultures, and (2) the continuous contact between two different languages and communities. These factors led to the discovery of translation as a solution that overcomes the barrier of language and as a means of conveying ideas, knowledge, and experience from one culture to another.

Translation during the $19^{\text {th }}$ century was a one-way communication between the prominent men of letters and the educated readers abroad. It was developed during the $20^{\text {th }}$ century, and it was called the "age of translation", or the "age of reproduction". Translation in the $20^{\text {th }}$ century acquired a political importance because of the emergence of the United Nations and other International Organizations. Added to this, the increase in technology, the efforts that were made to bring technology to developing countries, and the increased need for communication among the nations of the world.

\subsection{Translation as a Polysemous Term}

Theorists of translation believe that the term translation itself is polysemous in that it has several meanings. These meanings are as follows:

(1) It can refer to the general subject field, an interdisciplinary field, which spans other disciplines such as linguistics, phonetics, phonology, morphology, syntax, 


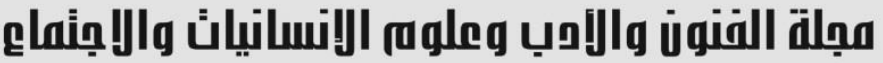 \\ Journal of Arts, Literature, Humanities and Social Sciences www.jalhss.com

semantics, pragmatics, semiotics, discourse analysis, psycholinguistics, sociolinguistics, logic, and communication theory.

(2) It can refer to the process (translating) which means the act of producing the translation or the act of decoding the SLT and encoding the TLT. With these terms in mind, the translation process can be broken down into two types of activity: (1) understanding an ST and formulating a TT. These do not occur successively, but simultaneously.

(3) It can refer to the product (translated text) which means the text that has been translated or resulted from the process of decoding the SLT and encoding the TLT. At the extreme of SL bias is interlinear translation, where the TT does not necessarily respect TL grammar, but has grammatical units corresponding as closely as possible to every grammatical unit of the ST.

(4) It can refer to the useful technique in foreign language teaching which is called the "Grammar Translation Method". According to this method, translation is viewed as the search for the correct TL equivalent lexicon/sentence via grammar.

(5) It can refer to the "Applied Translation Studies" which includes inter alia translation, pedagogy, and translation criticism or assessment. The term "Applied Translation Studies" is used to describe the discipline which concerns itself with the problems raised by the production and description of translations.

(6) It can refer to the cultural act, an act of communication across cultures. In fact, translation always involves both language and culture simply because the two cannot really be separated. Language is culturally embedded: it both expresses and shapes cultural reality, and the meanings of linguistic items, be they words or larger segments of text, can only be understood when considered together within the cultural context in which these linguistic items are used. In the process of translation ; therefore, not only the two languages but also the two cultures come into contact. In this sense, translation is a form of intercultural communication.

(7) It may refer to contrastive linguistics. This means that particular attention is paid to the original text as an example of how a particular language works, with a view to noting how it contrasts with the language into which it is to be translated. There is ; however, a major difference between both. While contrastive linguists are interested in equivalences of linguistic categories within and across languages, translation theorists focus on equivalence in texts, in the actual use of the languages and their component parts in communicative situations.

(8) It can refer to some linguistic activities such as summarizing or paraphrasing (intra-lingual translation). Although such activities resemble transl adapt it for different groups of people with different needs and expectations. 


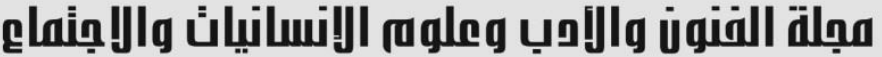

Journal of Arts, Literature, Humanities and Social Sciences www.jalhss.com

(9) It can refer to interpreting (e.g. conference interpreting). In professional conference interpreting, a distinction is usually made between simultaneous and consecutive interpreting. In simultaneous interpreting, the act of interpreting is carried, while the speaker is still talking ; in consecutive interpreting, interpreting will occur after the speaker finishes. In interpreting, on the other hand, a text is transformed into a new text in another language, which is, as a rule, orally available only once. Besides, conference interpreting in national or international environments, another type of interpreting, known as "community interpreting". (sometimes also called "public service interpreting" or "dialogue interpreting") has recently gained importance. Given increasing international migration and the resulting mixture of linguistic background, community interpreting fulfils an important mediating function in that it facilitates communication between officials and lay persons who speak different languages. Community interpreting is almost always carried out consecutively (face-to-face or over the phone). It takes place, for instance, in police or immigration departments, social welfare centre, hospitals, schools or prisons, and is either carried out by untrained "natural interpreters" such as bilingual relatives and friends, or by professional experts in specialist (legal, medical, etc.) domains. The interpreter has to interpret for both parties, thus switching between both languages. Untrained volunteer community interpreters are often neither neutral nor objective when they interpret for a relative or a friend ; rather, they tend to take the side of whoever they are helping out in an institutional context. A type of interpreting which is similar to community interpreting is "liaison interpreting", but here the interpreting is done between persons of equal status in business and technical meeting.

From what has been said so far, we can say that translation is a kind of secondary communication with both a limiting and an enabling function. It can be defined as a process of replacing a text in one language by an equivalent text in another. However, translation can be distinguished as a linguistic act and as intercultural communication.

\subsection{Toward Contemporary Translation Theory}

Steiner (1998) in his detailed, idiosyncratic classification of the early history of translation theory, lists a small number of fourteen writers who represent "very nearly the sum total of those who have said anything fundamental or new about translation". This list includes St Jerome, Luther, Dryden and Schleiermacher and also takes us into the twentieth century with Ezra Pound and Walter Benjamin, amongst others. Steiner (1998) in fact describes as "very small" the range of theoretical ideas covered in this period:

We have seen how much of the theory of translation, if there is one as distinct from idealized recipes, pivots monotonously around undefined alternatives: "letter" or "spirit", "word" or "sense". The dichotomy is 


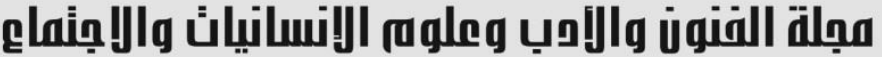

Journal of Arts, Literature, Humanities and Social Sciences www.jalhss.com

\section{assumed to have analyzable meaning. This is the central epistemological weakness and sleight of hand.}

(Steiner 1998)

Other modern theoreticians concur that the main problem with writings on translation in this period was that the criteria for judgements were vague and subjective (Bassnett, 1991) and the judgements themselves were highly normative. As a reaction against such vagueness and contradictions, translation theory in the second half of the twentieth century made various attempts to redefine the concepts "literal" and "free" in operational terms, to describe "meaning" in scientific terms, and to put together systematic taxonomies of translation phenomena. These approaches form the core of the following chapters in this book.

\subsection{Translation in the Arab World in the $20^{\text {th }}$ Century:}

France, Britain and Italy had had their designs on various parts of the Arab World since the early nineteenth century, and the Ottoman Empire was growing too weak to defend its territories. By the early part of the twentieth century most of the Arab World was under occupation, with the British in Egypt, Palestine, Sudan and Iraq, the French in North Africa and Syria, and the Italians in Libya. For the first time in many centuries, the Arab World lacked a common political leadership. This and the subsequent rise of individual nation states meant that cultural development in the area, and with it translation activity, began to diverge considerably. The territory is simply too large and too diverse to be covered in a short exposition.

In this century there have been efforts to develop a coherent pan-Arab programme of translation. One such attempt took place in Tunis in (1979), under the ages of the Arab Organization for Education, Culture and Science (Fi al-Adab wa-1ta'lif wa-l-tarjama, 1993). The recommendations of this committee included developing common criteria for selecting texts for translation, reassessing the status of translators in the Arab World, establishing a coherent policy for language learning and translator training, setting up regional and Arab unions to represent translators, and encouraging theoretical research in translation. This ambitious programme does not seem to have been followed up so far.

Translation training programmes exist in various parts of the Arab World, either in the form of independent institutions (as in the case of the king Fahd School of Translation in Tangier) or university departments or centres within departments (for example in Yarmuk University, Jordan, and Alexandria University). Iraq had a thriving school of translation (al-Mustansiriyya) and a professional organization for translators prior to the Gulf War. There is a Department of Translation at the University of Mosul which provides the governorate of Nineva with translators. 


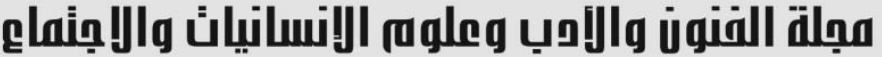

Journal of Arts, Literature, Humanities and Social Sciences www.jalhss.com

The King Fahd School of Translation in Tangier publishes a bi-annual scholarly journal of translation under the title of Turjumān (Translator); this contains articles in Arabic, English, French and Spanish.

\section{Defining Translation}

Translation is not a new comer to the academic scene. It has been widely practised in the course of human history. In present day globalised world, human communication is heavily dependent on translation. The results of this human activity provide a great deal of information about the ancient cultures as well as different present day cultures and help in widening intercultural exchanges. In Bassnett's words, translation, can be seen as the portal through which the past can be accessed. It opens up greater opportunities to remind contemporary readers about lost civilization.

Throughout the history of research into translation, the phenomenon has been variously delimited. In fact, there exists a myriad of definitions of the concept of 'translation'. Some are of an analogical nature, others are of a formal nature; some have a restricted sense, whereas others have abroad sense. Each of these definitions mirrors a specific theoretical tendency toward translation and reflects the theoretical approach underpinning it.

Catford (1965), for example, argues that translation is an act of replacing linguistic units from a source language to a target language. He wrote, "translation is the replacement of textual material in one language (SL) by equivalent textual material in another language (TL)". What is important for him is to maintain kind of 'equivalence' between the source text (ST) and the target text (TT)

On the same line of thought, Jakobson (1966) sees translation as a linguistic operation which deals with linguistic signs as such. This process can take place between two different languages as well as within the same language. Yet, the verbal signs remain the basis of translation in both cases. Seen from this perspective, translation is restricted and limited to the linguistic material only, i.e. the focus is laid on the linguistic aspects of the translation process. However, Bassnett (2007) categorically deems that translation should be regarded as a series of shifts at both the linguistic and the cultural levels within which a given text is embedded.

Another different view of translation is given by Nida and Taber (1982) who wrote "translating consists in reproducing in the receptor language the closest natural equivalent of the source-language message, first in terms of meaning and secondly in terms of style". Accordingly, they focus on both content and form of the message to reproduce the same effect on the source text.

The above definitions also confirm the importance of 'equivalence' which underlies the following definitions, among others, given by Meetham and Hudson (1972): 


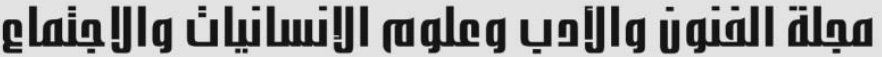

Journal of Arts, Literature, Humanities and Social Sciences www.jalhss.com

"Translation is the replacement of a text in one language by an equivalent text in a second language".

On the other hand, functionalists like Nord (2007) view translation differently. For them, "translation is the production of a functional target text maintaining a relationship with a given source text that is specified according to the intended or demanded function of the target text".

Nord (2007), however, distinguishes between two senses of translation: wide and narrow. For him, "translation is, in a narrow sense, any translational action where a source text is transferred to a target culture and language". According to the form and presentation of the source text and to the correctibility of the target text we distinguish between oral translation (interpreting) and written translation (translation in the narrow sense).

Widening the above definitions, Sager (1994) maintains that translation should reflect the environment in which the professional translation activity takes place. For him "translation is an extremely motivated industrial activity, supported by information technology, which is diversified in response to the particular needs of this form of communication".

In a similar vein, Koller (1995) describes translation as a "text processing activity and simultaneously highlights the significance of equivalence". For him, "translation can be understood as the result of a text-processing activity, by means of which a sourcelanguage text between the resulting text in L2 (the target-language text) and the source text L1 (the source-language text) there exists a relationship, or equivalence relation".

To sum up, it is apparent that Nida and Taber's definition may serve as a basis for our concept of translation as a TL product which is as semantically accurate, grammatically correct, stylistically effective and textually coherent as the SL text. In other words, the translator's main attention should not be focused only on the accurate semantic transference of SL message into the TL, but also on the appropriate syntax and diction in the TL, which are explicitly the translator's (not the source author's) domain of activity which displays his true competence. Indeed, according to Wilss (1969), the notion of translation competence, "is aptly assessed in transfer situations that require at least some degree of adaptation to new and challenging textual demands". He describes such situations as "accommodatory situations" which need "structural adjustment" and generally textual manipulation. In tasks with inevitable intricacies of performance his approach to translating expressive, emotive or expository texts in particular is deemed to be creativity-oriented, that is, hermeneutic/manipulation rather than routine-oriented. In the latter approach, SL 
words are mechanically replaced by their TL equivalents, albeit one-to-one equivalence rarely, if ever, exists between languages.

\subsection{Translation as Process and Product}

Translation can be viewed from different perspectives, that of a 'process' and that of a 'product'. As a process, translation consists of turning a message from one language into another. The transmitted message can be in the form of an expression, an utterance or even a piece of music. Seen from another perspective, translation can be seen as the end product of this process, i.e. the translated text.

In addition to this twofold division, there exists a third variable, namely that put forward by Bell. He (1991) differentiated between "the abstract concept which encompasses both the process of translating and the product of that process", i.e. translation proper, translating (the process), and a translation (the product).

\subsection{Translation in Terms of Equivalence:}

Equivalence is a term used by many writers to describe the nature and the extent of the relationships which exist between SL and TL texts or smaller linguistic units. As such, equivalence is in some senses the intralingual counterpart of synonymy within a single language and sometimes across languages (Shuttleworth and Cowie, 1997). Hence, one should know that Jakobson's (1966) famous slogan "equivalence is difference" highlights the added complications which are associated with it.

The phenomenon of equivalence is indeed complex and its concept is still controversial. Hermans (1995), for example, has described it as a "troubled notion: part of the problem stems from the fact that the term is also standard polysemous English word, with the result that the precise sense in which translation equivalence is understood varies from one translator to another. Catford (1965), for instance, defined translation as the replacement of textual material in one language by the textual material in another language, and argues that one of the central tasks of translation is that of "defining the nature and conditions of translation equivalence". Catford's view of equivalence as something essentially quantifiable - and of translation as simply a matter of replacing each SL item with the most suitable TL equivalent, chosen from a loss of all the limitations of linguistics at that time" (de Beaugrande, 1978). SnellHornby (1995) believes that such a view "presupposes a degree of symmetry between languages, and even distorts the basic problems of translation" in that it reduces the translation process to a mere linguistic exercise, ignoring textual, structural, lexical, cultural and other situational factors, which it is now agreed upon to play an important role in translation. This view has enabled a number of scholars to subdivide the notion of equivalence in various ways. Thus, some have distinguished between the 
equivalence found at the levels of different "units of translation", whereas others have formulated a number of complete equivalence typologies, such as Nida's (1964) "dynamic and formal equivalence" and Kade's (1968) total (one-to-one), facultative (one-to-many), approximative (one-to-part) and zero (one-to-one) equivalence. Koller's (1992) is more wide-ranging denotative, connotative, textual-normative (i.e. text type-based), pragmatic and formal-aesthetic equivalence, and Popovic's (1976) linguistic, paradigmatic, stylistic and textual equivalence. Each of these individual categories of equivalence encapsulated a particular type of ST and TT relationships, although few can be said to be complete in themselves, whereas some (for instance dynamic and formal equivalence) are mutually exclusive. Consequently, the term, which has originally been introduced in order to define translation scientifically, has become increasingly complex and fragmented. Many theoreticians of translation have suggested other terms such as 'similarity', 'analogy' 'correspondence' or 'matching' (cf. Hermans, 1995 and Shuttleworth and Cowie, 1997). Toury (1980) insists on viewing every translation as "a concrete act of performance, and proposes that each TT should be approached via the particular "norms" under which it was produced, arguing that these norms determine "the equivalence" manifested by actual translation" (Toury, 1995). Likewise Reiss and Vermeer (1989) also interpret equivalence on the basis of each individual text, but unlike Toury (1980), in terms of function and communicative effect. For them, there are no particular features of ST which automatically need to be preserved in the translation process; however, they reserve the term 'equivalence' for this instance in which ST and TT fulfil the same communicative function (for further details, see Wilss, 1994; Pym, 1992; Shuttleworth and Cowie, 1997).

\subsection{Formal Correspondence, Transference and Translation Shifts}

Translation is an activity - and there is little use in theorising about an activity which has been done badly. Cycling and swimming are also activities. Noting the awkward gestures of a man falling off a bicycle or someone who cannot keep head above water would hardly lead to conclusions with any sound theoretical value. Although the line separating success or failure for these two sports is clearly marked and this is by no means the case with translation, any theory on translation should nevertheless base itself on successful examples of that activity.

For the time being, let us set the standard of a successful translation by using a negative definition: a translation is successful if it contains neither errors of language nor errors of method. We all recognise errors of language. The errors of method I refer to can be identified mainly by the presence of far too many correspondences in a translation. 
There are countless degrees of performance between the Olympic swimming champion and the swimmer who knows enough not to drown, or between a cyclist in the Tour de France and the postman doing his rounds. Likewise, there are countless gradations of successful translations; from the exquisite translations of some great texts to those which are valid because they are error-free. An absence of errors is the minimum standard which can be set because there is no other obvious standard as in other activities. Consequently, below this standard we would not be dealing with translation as we understand it, and beyond it we would be in the field of evaluation. Put simply, interpretive translation is made of equivalence, linguistic translation of correspondences. The example below illustrating the difference between the two is taken from chapter XIV of Canary Row by John Steinbeck (1945) and its Arabic translation.

\subsection{What is Equivalence?}

Let is see how the beginning of chapter XIV of Canary Row is translated:

\section{(E)}

Early morning is a time of magic in Canary Row. In the grey time after the light has come and before the sun has risen, the Row seems to hang suspended out of time in a silvery light.
(A)

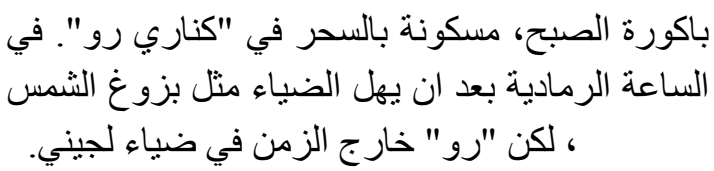

(Literally: 'Dawn is a magical moment in Sardine Street. When the sun has not yet pierced the grey horizon, the Street seems suspended out of time, enveloped in a silver glow').

The sense in Arabic is the same as in English even though the English and Arabic words only rarely correspond. English language meanings have contributed to the sense of the text being perceived but they have not all been translated as such; reexpression was determined by the constraints of Arabic and the stylistic preferences of the translator. The text and its Arabic translation can be said to be equivalent.

One would be tempted to think that the controversies which oppose the supporters of faithfulness to those of freedom will last as long as we speak of 'translation' as an undifferentiated whole requiring either faithfulness or freedom - a choice between the letter or the spirit - whereas correspondences are needed to render the letter when necessary and equivalents to render the spirit.

The freedom vs. faithfulness debate is solved by the equivalence/ correspondence duality of all successful translations. Correspondences are necessary when one is 
dealing with proper nouns, figures and technical terms. Other correspondences arise $a$ posteriori from the actualisation of words; as opposed to the first group, these occur during the process of translation - they are not applicable in all circumstances but are produced by the reformulation of sense. On the other hand, correspondences which have been used thousands of times before may not apply in a new text where sense calls for them to be replaced by equivalents. Though is not enclosed in a linguistic frame and translators coin their expression based on the state of things which have to be designated hic et nunc, not on previously established correspondences between words. One should not forget that existing correspondences are products of translations which have preceded the realisation of a new translation, whereas equivalents refer to actual realities - whether concrete or abstract - and their originality is due to the specificity of the reality designated.

Correspondence and equivalence are intimately linked in the process of translation. Neither one ever completely prevails over the other.

\section{Conclusion}

Translation is a kind of secondary communication with both a limiting and an enabling function. It can be defined as a process of replacing a text in one language by an equivalent text in another. It can also be defined in terms of "meaning", "monitoring", "equivalence", "transference", product, intercultural communication, among many other types. The three basic features of translation are thus text, equivalence, and process. Traditionally, one can distinguish between translation as a linguistic act and translation as intercultural communication.

In the previous sections, we had a glimpse of how complex translation is. This complexity comes about not only because of the problems of pinning down the meaning of an original text, but because of the need to restate that meaning in another text. Different perspectives on translation have focused on different aspects of that process.

Given its complexity, translation can, and indeed must be approached from different perspectives, linguistic, cultural, socio-political literary, purpose-oriented. Linguistic perspectives on translation, which focus on the original text, have recently widened their scope considerably-from a concern with lexical and semantic meaning to embracing functional and pragmatic views of language. Scholars who sympathize with the other more psychosocial, more "subjective" perspective on translation sometimes deny the very relevance of the original text, emphasizing the importance of the relevance and effect of the target text. A focus on variable, culturally conditioned interpretations of texts, and on the purpose of a translation are the most recent, late twentieth century contributions to the field. 
A translated text can never be identical to its original; it can only be equivalent to it in certain respects. These can be systematized in the form of five equivalence frameworks, not all of which can be fulfilled simultaneously. The choice a translator is forced to make between differently equivalent expressions depends in each individual case on the hierarchy of equivalence demands he sets up for himself, or is asked to follow. Translation is only possible with reference to the concept of equivalence, for there can be no exact transference of meaning across texts in different languages, only an approximation appropriate to purpose. But how far that purpose can be achieved is also dependent on the limits of translatability.

Despite the fact that many serious attempts have been made to arrive at a unified theory of translation, linguists, semanticists, pragmaticists, discourse analysts, contrastive analysts are still in doubt about such a possibility. The idea of formulating a reliable theory is of a great significance, since it would systematize the methods and procedures of translation. It was useful when we referred briefly to different views on this matter put forward by linguists and translation theorists. So if we are studying translation, or the translating process, we need some preliminary model of this kind in order to orient ourselves, to give ourselves an initial framework within which we can begin to think. The question is what is exactly a model?

A model is a construction that represents some aspect of reality, but not all models represent something in such a straightforward way. Theoretical models represent their objects in more abstract ways; they are often based on assumptions about how something is structured, or how it might be related to other phenomena. These models are attempts to construct images of the object of study, images that hopefully make it easier to visualize, understand and analyze. A theoretical model is like a map showing what are thought to be the most important features of the object. Different maps of the same terrain might highlight different features just as we can have maps showing national borders or different vegetation areas, or economic maps showing different areas of wealth and poverty.

\section{References}

1. Al-Sulaimaan, M. M. D. and Sa'eed, A. A. (2007): "Some Problems of Translating Metaphorical Expressions in the Shakespearean Tragedy Macbeth into Arabic". In: Adab Al-Rafidayn, No.46, pp.109-137.

2. Bell, R. T. (1991): Translation and Translating: Theory and Practice, London and New York: Longman.

3. Bassnett, S. (1991): Translation Studies, London and New York: Routledge. 


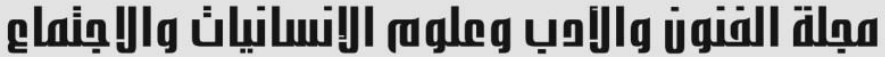

Journal of Arts, Literature, Humanities and Social Sciences

www.jalhss.com

4. Catford, J. C. (1965): A Linguistic Theory of Translation, London: Oxford University Press.

5. Hatim, B. (1997): The Translator as Communicator, London and New York: Routledge.

6. Holmes, J. S. Frans de Haan, and Anton Popovit (eds.) (1970): The Nature of Translation, The Hague: Mouton.

7. Jakobson, R. (1966): "On Linguistic Aspects of Translation", in Brower, A. A. (ed.). On Translation, New York: Oxford University Press, A Galaxy Book, pp. 232239.

8. Hermans, T. (ed.) (1999): Translation in Systems, Manchester: St Jerome.

9. Steiner, G. (1998): After Babel: Aspects of Language and Translation, Oxford: Oxford University Press.

10. Kade, O. (1968): Zufall und Gesetzmäßigkeiten in der Übersetzung, Leipzig: VEB Enzyklopädie.

11. Koller, W. (1995): "The Concept of Equivalence and the Object of Translation Studies" Target, 7.

12. Lawedowski, Boguslave, P. (1978): Meaning and Translation: Philosophical and Linguistic Approaches, London: Duckworth.

13. Meethan, A and Hudson, R., (1972): Encyclopedia in Linguistics, Information and Control, Oxford: Pergamon Press.

14. Nida, E. and Taber, C. R. (1982): The Theory and Practice of Translation, Leiden: E. J. Brill.

15. Nord, C. (2007): Translating as a Purposeful Activity: Functionalist Approaches Explained, Manchester: St Jerome

16. Nord, C. (1991): Translating as a Purposeful Activity: Functionalist Approaches Explained, Manchester: St Jerome.

17. Popovič, A. (1976): Dictionary for the Analysis of Literary Translation, i. Edmonton: Universityof Alberta.

18. Pym, A. (1992a): Translation and Text Transfer: An Essay on the Principles of Intercultural Communication, Frankfurt am Main: Peter Lang.

19. Sager, J.C. (1994): Language Engineering and Translation: Consequences of Auto- mation, Amsterdam: John Benjamins.

20. Steinbeck, J. (1945): Cannery Row, London: Penguin.

21. Snell-Hornby, M. F. P. and Kaindl, K. (eds.) (1996): Trtanslation as Intercultural Communication, Amsterdam and Philadelphia, PA: John Benjamins.

22. Shuttleworth, M. and Cowie M. (1997): A Dictionary of Translation Studies, Manchester: St. Jerome Publishing.

23. Toury G. (1995): Descriptive Translation Studies-and Beyond, Amsterdam and Philadelphia, PA: John Benjamins.

24. Toury, G. (1980): In Search of a Theory of Translation, Tel Aviv: The Porter Institute.

25. Wilss, W. (1982): The Science of Translation, Tubingen: Narr. 